\title{
Emerald $\begin{gathered}\text { Evidence-based HRM: } \\ \text { a global forum for } \\ \text { empirical scholarship }\end{gathered}$
}

An exploratory study of job insecurity in relation to household registration, employment contract, and job satisfaction in Chinese state-owned enterprises

\begin{tabular}{|r|l|}
\hline Journal: & Evidence-based HRM: a global forum for empirical scholarship \\
\hline Manuscript ID & EBHRM-09-2015-0039.R3 \\
\hline Manuscript Type: & Research Paper \\
\hline Keywords: & $\begin{array}{l}\text { Job Insecurity, Job Satisfaction, Household Registration, Employment } \\
\text { Contract, Social Safety Net, Social Welfare, China, State-owned Enterprise, } \\
\text { Institutions, Equality }\end{array}$ \\
\hline \multicolumn{2}{|l}{} \\
\hline
\end{tabular}




\title{
An exploratory study of job insecurity in relation to
}

\author{
household registration, employment contract, and job \\ satisfaction in Chinese state-owned enterprises
}

\begin{abstract}
Purpose - The paper examines the influence of the household registration and of employment contract on employee job insecurity in Chinese state-owned enterprises.

The relationships between job satisfaction and the two components of job insecurity are also analysed.

Design/methodology/approach - The research uses original data collected through a questionnaire survey in six Chinese state-owned enterprises. 309 samples are analysed mainly using hierarchical regression analysis.

Findings - The research finds household registration is a predictor of job insecurity while employment contract is not. Job satisfaction is found to be positively related to one of the components of job insecurity: the perceived severity of job loss.

Social implications - To improve job security of the employees who are in vulnerable positions, improving the equality of social safety net is significant. In China, household registration causes unequal access to social welfare and employment opportunities; improving the equality may be more significant than seeking for permanent employment.

Originality/value - The research suggests two levels of factors influencing job insecurity: the macro level factors include the institutional configurations of social safety net; the micro level factors include employment contract. The macro level factors have fundamental influence while the micro level factors are more apparent. The micro level factors may manifest their influence only when the macro level factors equally cover all the employees. The macro level factors may also intermediate the relationship between job insecurity and satisfaction.
\end{abstract}

Keywords Job insecurity, Job satisfaction, Household registration, Employment contract, Social safety net, Social welfare, China, State-owned enterprise, Institutions, Equality

Paper type Research paper 


\section{Introduction}

Job insecurity is defined as an employee's perception of threat and powerlessness in relation to the employee's present job (Greenhalgh and Rosenblatt, 1984). It can be summarized to have two components: the perceived likelihood of job loss and the perceived severity of the loss (Ashford et al., 1989; Jacobson, 1991; Klandermans et al., 2010). Job insecurity leads to negative attitudinal reactions such as reduced organizational commitment and trust (Ashford et al., 1989; Coyle-Shapiro and Kessler 2000; De Witte et al., 2010). It can also cause poor job performance and increased job withdrawal (Sverker et al., 2002; Cheng and Chan, 2008), though maybe arguably to different extent between temporary and permanent employees (De Cuyper and De Witte, 2007; Klandermans et al., 2010; Klein Hesselink and Van Vuuren, 1999). It may affect employee health and have spillover effects on marital relationships (Greenhalgh and Rosenblatt 2010). Hence, job insecurity can be harmful and costly at both organizational and individual levels (Sverke et al., 2002). Therefore, it is significant to study job insecurity.

The antecedents of job insecurity have been studied on two levels: the macro level mainly includes institutional configurations of societal support; the micro level includes employment contract types, trust between employees and employers. 
On the macro level, analyses of job insecurity need to take social safety net into account in terms of its strength and equality. Social safety net can be described as a country's institutional configurations including the construction of social welfare, the regulation of the labour market, and other societal supports (Blank, 1994; Debus et al., 2012). Previous research mainly studied the social-safety-net effect from the perspective of strength at the cross-country level: people are less concerned about losing their jobs if there are high levels of societal support for people without jobs in that country (Debus et al., 2012; König et al., 2011). However, this group of research ignored the equality of the safety net in terms of coverage and access: its underlying assumption was that all citizens in each country are equally covered by the safety net, and the citizens get equal access to the safety net. But, in China that is not the case: generally speaking, people with urban household registration are fully covered whereas people with rural household registration are not. Thus, at the intra-country level, the unequal coverage and its influence on employee job insecurity need to be studied. However, the literature from the equality perspective is limited. Using empirical data from the Chinese stateowned enterprises (SOEs), this research aims to contribute to the literature.

On the micro level, the employment contract has been considered to have possible impact on job insecurity. During the last three decades, employment types in the Chinese SOEs have been undergoing significant changes. Before the economic 
reform in the $1980 \mathrm{~s}$, permanent employment was the majority and was protected. Since then, temporary employment and redundancy have been greatly increased. Probst and Lawler (2006) noted that job insecurity becomes a growing concern for most employees in the SOEs. It could be assumed that temporary employment might cause higher level of job insecurity because temporary employees are more likely to be laid off. Nevertheless, there has been a debate about this assumption. Findings by Klein Hesselink and Van Vuuren (1999) and Parker et al. (2002) support the assumption. However, Jacobson (1991) and Klandermans et al. (1991, 2010) argued that the above research only measured one component of job insecurity - the perceived likelihood of job loss and ignored the other component - the perceived severity of job loss. They therefore argued that, for temporary employees, the perceived severity of job loss is often low as they expect their jobs will be terminated and are used to the kind of working and living style. Thus, temporary employees would not suffer stronger job insecurity. Following this argument, this research aims to examine the relationship between employment contract types and job insecurity in the Chinese SOEs.

One of the consequences of job insecurity is low job satisfaction (Coyle-Shapiro and Kessler, 2000; De Witte et al., 2010). Job satisfaction was found to be negatively related to job insecurity (Ashford et al., 1989; Sverke et al., 2002; Reisel et al., 2010). Nevertheless, job insecurity has two components: the perceived likelihood of job loss 
and the perceived severity of the loss, and there is little research into which component is, and how it is, related to job satisfaction. The research also aims to contribute to this unknown area.

Further, previous research into the micro level antecedents and consequences of job insecurity ignored the possible impact from the macro level, in particular, social safety net. For instance, Wong, et al. (2005) studied Chinese workers' responses to job insecurity in joint ventures and SOEs without considering the influence of the unequal social-safety-net configurations, not distinguishing rural and urban household registered employees. This exploratory research therefore aims to explore the relationship between job insecurity and employment contract and job satisfaction under the macro level context - Chinese social safety net. Thus, the research generates initial insights into this unknown area and may lead to extensive studies.

Focusing on employees in the Chinese SOEs, this exploratory research is threefold. First, it analyses how the unequal configurations of social safety net influence job insecurity, extending our understanding of social-safety-net effect from the strength perspective to equality perspective. Second, under the condition of unequal socialsafety-net configurations, the research examines the relationship between employment contract types and job insecurity, contributing to the debate about whether temporary employment causes higher job insecurity. Third, under the same condition, the research 
specifically studies how each component of job insecurity is related to job satisfaction, deepening our understanding of the relationship between the two subjects.

\section{Background}

The research is based on the fact that the Chinese social safety net has never been equal to the residents. The social safety net is fundamentally operated through the highly institutionalized Household Registration System ('hukou' in Chinese). The system classifies the residents into two groups, namely urban and rural registered residents (Liu, 2005; Solinger, 1999; Wang, 2004). There are insurmountable differences between the two groups in terms of access to social welfare and SOE employment.

China's social welfare system has never covered all the residents equally. Before the 1990s, the system only covered urban registered residents and could only be accessed through permanent employment in the SOEs, government, and other state or public owned organizations (Chan et al., 1992; Walder, 1995). In the 1990s reforms, the government tried to set up a separate rural welfare system, but failed to construct an effective one (Zheng and Sun, 2008). Recent reforms such as the new national health care and pension schemes still provide very limited support to rural registered residents. In contrast, urban registered residents are provided with heavily subsidized social welfare: education, health care, and a broad range of benefits (Liu, 2005; Wang, 2004; 
Whyte, 2010). In addition, most of the educational and health care resources are located in the urban areas, whereby rural residents' access to these welfare is very difficult.

Another major benefit for urban registered residents is their prior access to permanent jobs in SOEs. The SOEs provide their own workplace welfare and workplace benefits which are supplement to China's weak social welfare system. However, the workplace welfare and benefits tend to favour permanent employees (today, all "permanent contracts" have been transferred to long-term contracts which are reviewed about every five years and normally are on-going. For easy understanding and consistency, the research still uses the term "permanent contract"). Under China's Labour Law, the workplace welfare should cover both permanent and temporary employees and consists of five separate funds: pension, industrial accident, housing, unemployment, and medical insurance. Both employers and employees contribute to these founds based on employees' wage levels. As temporary employees get the lowest wage, they therefore get the lowest welfare. The workplace benefits, mainly including additional housing and healthcare, are based on an employee's contract type and work position. A permanent contract and higher position can lead to greater benefits. Temporary employees are generally excluded from the formal structure of these benefits. As a result, permanent employees are the beneficiaries (Chan et al., 1992; 
Walder, 1995); whilst temporary employees not only get the lowest workplace welfare and hardly any workplace benefits, but are also at the highest risk of redundancy.

A permanent employment contract in the SOEs can lead to greater welfare and benefits. However, the opportunity to get the contract has never been equal between the rural and urban registered residents. Before the 1980s, urban registered residents were officially given priority to work in the industrial sector, especially in SOEs; rural registered residents were only entitled to work in the agricultural sector (Chan et al., 1992; Whyte, 2010). Since then, new regulations have been issued to make rural registered people's access to industrial employment easier, largely in non-SOEs (Frenkel, 2001; Solinger, 2006). However, recruitment policies in the SOEs still favour urban residents, restricting rural residents' access to permanent employment. Thus, the employment and benefit inequalities between rural and urban registered residents remain considerable.

Further, unlike in the West, change of household registration is not based on where a resident lives. The two types of registration were originally decided by whether the people were distributed to work in the agricultural or industrial sector by the state in the 1950s. Since then, people generally inherit the registration from their parents. Because urban registration can lead to greater benefits, change from rural to urban registration has been tightly restricted, mainly by setting quotas (Bian, 2002; Chan et 
al., 1992; Li, 2001). For instance, ever since 1980, the quota has been set at 0.2 to $0.5 \%$ of the total rural registered population (Wang, 2004), though there has been a much larger proportion of rural registered population working in the urban areas (mainly in non-SOEs). As a result, the major beneficiaries of the Chinese social safety net are urban registered residents, especially those holding permanent contracts in the SOEs.

This unequal social safety net might be expected to have a substantial influence on job insecurity.

\section{Hypotheses development}

\subsection{Social safety net and job insecurity}

At the macro level, a country's institutional configurations have been considered to affect job insecurity. Lazarus and Folkman (1984) pointed out that individuals are embedded in higher level societal systems, it therefore can be assumed that factors from the country context affect an individual's appraisal of job insecurity. Societal support, as a part of national institutions, "increases the individual's ability to cope with stressful organizational situations by buffering the individual's life outside the organization (Greenhalgh and Rosenblatt 1984, p. 445)”. In line with this assumption, Borg and Elizur (1992)'s empirical findings in Germany showed that providing more support contributes to reducing job insecurity. König et al. (2011), in their study of working 
students, found more negative reactions to job insecurity in the United States of America (USA), a country with a relatively weak social safety net, compared with Switzerland, a country with a relatively strong social safety net. Debus et al. (2012), using representative samples drawn from 24 countries (but not including China), found that employees in countries with stronger social safety nets had fewer negative reactions to job insecurity. These findings highlight the negative relationship between social safety net and job insecurity at the cross-country level.

At the intra-country level, based on the inequality that an urban household registration represents greater societal support in China, Shi (2015) found that temporary employees with rural registrations have higher job insecurity than those with urban registrations in the SOEs. However, permanent employees were not studied. Covering both permanent and temporary employees, considering the negative relationship between social safety net and job insecurity, and considering the two components of job insecurity, the following hypotheses were proposed.

H1a. In the Chinese SOEs, rural registered employees have higher levels of concern on the perceived likelihood of job loss than urban registered employees.

H1b. In the Chinese SOEs, rural registered employees have higher levels of concern on the perceived severity of job loss than urban registered employees. 


\subsection{Employment contract and job insecurity}

Unsurprisingly, researchers such like Klein Hesselink and Van Vuuren (1999), and Parker et al. (2002) found temporary employees display more job insecurity than permanent ones. They considered the major reason is that temporary contracts are far more likely to lead to job loss. However, there have been arguments against this simplistic conclusion.

Klandermans et al. $(1991,2010)$ argued that job insecurity not only consists of the perceived probability of job loss, but also the perceived severity of the loss. For temporary employees, the former is often high, but the latter often low as they expect their jobs will be terminated and are used to this working and living style. Jacobson (1991, p. 33) explained it as: "I can only be worried about losing my job if I think it is likely that I will lose it. But, if I do not care about my job, the likelihood of losing my job is of little concern to me". On the contrary, permanent employees estimate the probability of losing their job as low, but the severity as high. Therefore, these researchers predicted that temporary workers would not suffer stronger job insecurity. Some recent studies support this opinion (Greenhalgh and Rosenblatt, 2010).

Klandermans et al. (1991, 2010) and Jacobson (1991)'s arguments are on the basis of the western social safety net which equally covers both temporary and permanent employees and provides them with sufficient living support. Temporary 
employees do not have to worry about their living after losing their jobs. But, in China it is different: jobless people can only get very limited societal support and their living is a concern. Hence, to the Chinese temporary employees, both the likelihood of losing jobs and the severity of the loss are supposed to be high. Hence, they are assumed to suffer higher job insecurity.

However, another influence from the Chinese social safety net should not be ignored: urban registered residents have more chance to work in the SOEs, including being temporary employees. As a result, most of temporary employees are urban registered residents. This might counteract the possible higher job insecurity from those with rural household registrations. Therefore, the temporary and permanent employees might not have different level of job insecurity. Thus, the research proposed the following hypotheses.

H2a. In the Chinese SOEs, temporary employees do not have higher level of concern on the perceived likelihood of job loss than permanent employees.

H2a. In the Chinese SOEs, temporary employees do not have higher level of concern on the perceived severity of job loss than permanent employees.

\subsection{Job insecurity and satisfaction}

Job satisfaction is considered to be one of the consequences of job insecurity (Ashford et al., 1989; Sverke et al., 2002). Ashford et al.'s survey in the northern USA and Reisel 
et al. (2010)'s survey of the part-time MBAs in the Southwest and West coast of USA found that job satisfaction is negatively related to job insecurity: the higher the insecurity, the lower the satisfaction. In line with these findings, the following hypotheses were proposed.

H3a. Job satisfaction is negatively related to the perceived likelihood of job loss in the Chinese SOEs.

H3b. Job satisfaction is negatively related to the perceived severity of job loss in the Chinese SOEs.

\section{Data collection and processing}

Data used in this research were from a work attitude questionnaire survey conducted by the author in 2007. The survey was conducted in six SOEs across four provinces in the East and Northeast of China, covering banking, construction, property, hotel, and power generating industries.

\subsection{Measurement and data processing}

There are broadly two methods measuring job insecurity: the global method measures job insecurity in its entirety, measuring the overall insecurity; the multi-dimensional method measures different facets or components of job insecurity (Sverker, et al. 2002; Greenhalgh and Rosenblatt 2010). The latter method normally uses a questionnaire 
including lengthy indicators. For instance, Ashford, et al. (1989) designed a 57indicator measuring 5 facets of job insecurity. Lee, et al. (2008) simplified it to a barebones method which still contains 14 items. This research only used two self-designed indicators respectively measuring two facets of job insecurity. The main reasons were as following: first, this was an exploratory research, only generating initial insights for extensive studies; second, this was a part of a work attitudes survey which limited the space for job insecurity study; third, if all the indicators were translated to Chinese language, the differences of context and wording between the indicators would be difficult to be distinguished by the respondents. This could confuse the respondents and cause inaccuracy of the measurement.

To measure the perceived likelihood of job loss, the respondents were asked to evaluate the statement that "I always worry about losing my job". A 5-point Likert scale was employed: from -2 to 2 representing "strongly disagree" to "strongly agree". To evaluate the perceived severity of job loss, the respondents were asked to evaluate the importance of job security. The importance was assumed to positively reflect the perceived severity. Again, a 5-point Likert scale was employed: from -2 to 2 representing "not important at all" to "very important".

Besides the above self-designed questions, a set of four questions from the 1998 Workplace Employee Relations Survey (cited from Cully and Woodland, 1998) were 
adopted to measure job satisfaction. The four questions respectively asked the respondents to evaluate their satisfaction with the amount of their influence, pay, scope of achievement, and the respect they get in the workplace. A 5-point Likert scale was employed from -2 to 2 representing "very dissatisfied" to "very satisfied". Means of the four items were used to represent the overall job satisfaction for further regression analysis.

To test the relationships between household registration, employment contract, and job insecurity, hierarchical multiple regression analysis was used. The two components of job insecurity were treated as the dependent factors in two separate analyses, while household registration and employment contract were treated as the independent factors. In each analysis, in the first step, gender, age, working years, marital status, parental status, and union membership status were entered as control factors; in the second step, household registration was entered; in the third step, employment contract was entered. The reason for entering household registration prior to employment contract is that household registration is a fundamental social identity prior to employment and it is a qualification for the SOE employment.

There was an additional self-evaluation question exploring the reasons for job insecurity. It was considered to be complementary to the hierarchical multiple regression analysis: employee's self-evaluation could help to find out the apparent 
reasons for job insecurity whilst the hierarchical multiple regression analysis could find out the fundamental reasons. The respondents were asked to rank their top three reasons from a list of 10 given factors using value 1, 2, and 3 (unranked factors were equally treated as value 4). The given factors included household registration, employment contract, education, title of post, practical skills, work experience, personal reasons, labour market, economy, and the industrial situation. The top three reasons between rural and urban registered employees and between permanent and temporary employees were compared. Chi-square test was used.

Hierarchical multiple regression analysis was used again to analyse the relationships between the two components of job insecurity and job satisfaction. In the first step, the same control factors used in the previous regression analysis were entered; in the second step, household registration and employment contract were entered as these were supposed to be the antecedents of job insecurity; in the third step, the two components of job insecurity were entered. Means of the four aspects of job satisfaction was used as the independent factor.

\subsection{Survey and fieldwork}

Because the survey was conducted in the Chinese language, the back translation methodology (Brislin, 1980) was used between two bilingual Chinese postgraduate students and the author. The rectified Chinese version was then used in a pilot. Staff 
from the HRM departments of two SOEs participated in pilot runs and small modifications were made as a result. The data from these pilots were excluded from the final data.

The volunteer respondents were employees who had no managerial work titles.

The author was present at each survey site where the questionnaires were given to all qualified volunteers together in a meeting. After the author simultaneously explained each question, the volunteers were asked to take the questionnaires away and then to return the completed questionnaires to a sealed box anonymously within the next three days. It gave the respondents more time to think through the questions, encouraging them to express their genuine attitudes. In addition, the interaction between the author, HRM managers and the respondents also provided an in-depth insight into the subject.

All the participated SOEs and employees have agreed that their data can be used for research purpose and are of course guaranteed anonymity.

\section{Findings}

\subsection{Sample characteristics}

309 valid samples were analysed. The samples consisted of $87 \%$ urban registered employees, being the majorities in both the temporary and permanent employee groups. This reflected urban registered people's priority of access to SOE employment. Being 
the minority, over half of the rural registered employees $(60 \%)$ were temporary employees.

There were more permanent employees $(69 \%)$ than temporary ones. The temporary employees were much younger: $51 \%$ of temporary employees compared to fewer than $10 \%$ of permanent employees were under 25 -year-old; $55 \%$ of temporary employees compared to fewer than $15 \%$ of permanent employees had working experience of less than 5 years. As permanent employees were older, it was not surprising to see that over $80 \%$ of them, compared to $47 \%$ of temporary employees, were married or had partners, and over $70 \%$ of them compared to $30 \%$ temporary employees were parents. Pearson correlation analysis also showed (see Table I) that temporary employees were significantly correlated with less work experience, younger age, and less marital and parental status. It also showed that less rural registered employees and temporary employees had trade union memberships than their counterparts. The samples contained $51 \%$ females who were almost evenly distributed across the studied employee groups.

$<$ Table I. Pearson correlations between selected factors in relation to job

insecurity and satisfaction about here $>>$

\subsection{Household registration, employment contract, and job insecurity}

Table II shows the results of the hierarchical regression analysis of the relationship 
between household registration, employment contract, and job insecurity.

$<<$ Table II. Hierarchical regression analysis of job insecurity about here >>

Regarding the worry about losing job, in step 1, after entering all the control factors, the model is significant $[F(6,278)=4.672, \rho<0.001]$. In step 2, after entering household registration, the model is still significant $[F(7,277)=9.518, \rho<0.001]$. It explained additional $10.2 \%$ of variation and this change is significant $(\rho<0.001)$. Of the three significant predictors (household registration, gender, and marital status), household registration is the most important predictor in this step $(\beta=-0.328, \rho<0.001)$. In the third step, after entering employment contract, the model is still significant $[\mathrm{F}(8,276)$ $=8.563, \rho<0.001]$; but, the change is not $\left(\Delta R^{2}=0.7 \%, \rho<0.05\right)$. Of the three significant predictors (household registration, gender, marital status), household registration, again, was the most important predictor $(\beta=-0.309, \rho<0.001)$; employment contract was not significant $(\beta=-0.097, \rho>0.05)$. The results indicated that household registration was negatively related to the perceived likelihood of job loss: rural registered employees had higher concerns on the possibility of job loss. Employment contract was not a predictor of this component of job insecurity. Thus, H1a and H2a were accepted.

Regarding the importance of job security, in step 1, after entering all the control factors, the model was not significant $[F(6,277)=2.067, \rho>0.05]$. In the second step, after entering household registration, the model was significant $[F(7,276)=2.351, \rho$ 
$<0.05)$. It explained additional $1.3 \%$ of variance and the change is significant $(\rho<0.05)$.

Household registration was the most important and the only predictor $(\beta=-0.119$, $\rho<0.05)$ in this step. In the third step, after entering employment contract, the model was still significant $[\mathrm{F}(8,275)=2.053, \rho<0.05)$. But, no significant change happened $\left(\Delta R^{2}\right.$ $=0, \rho>0.05)$. Both household registration and employment contract were not significant in this step. Thus, household registration was found to be negatively related to the importance of job security in the second model, while employment contract was not found to be related in the analysis. Therefore, $\mathrm{H} 1 \mathrm{~b}$ and $\mathrm{H} 2 \mathrm{~b}$ were true.

These results showed that rural registered employees had higher levels of concern on the two components of job insecurity than the urban registered ones, while temporary employees had the same level of concern as the permanent ones.

\subsection{Reasons for job insecurity}

The analysis of the reasons for job insecurity showed some interesting results.

In employee's self-evaluation, employment contract was ranked in the top three reasons for job insecurity by both rural and temporary employee groups (see Table III). Chi-square test found that the consideration of employment contract was significantly different between the rural and urban groups $\left[\chi^{2}(3, \mathrm{~N}=267)=12.17, \rho<0.05\right]$ and between the temporary and permanent employee groups $[\chi 2(3, \mathrm{~N}=207)=110.58, \rho$ 
$<0.05]$. It appeared that employees felt temporary contract impact their job insecurity, which seemed to be contradictive to previous hierarchical regression analysis.

\section{$<$ Table III. Self-evaluation of the top three reasons for job insecurity}

\section{about here $>>$ \\ 5.4 Job insecurity and satisfaction}

The Cronbach's Alpha for the 4-item measure of job satisfaction was 0.72, above the acceptable level 0.70 . To analyse the relationship between job insecurity and satisfaction, in the first step of the hierarchical regression analysis (see Table IV), after entering all the control factors, the model was not significant $[F(6,277)=2.009, \rho$ $>0.05]$. In the second step, after entering household registration and employment contract, the model was significant $[F(8,275)=1.998, \rho<0.05]$. R-square increased $1.3 \%$; however the change was not significant. The most important predictor here was marital status $(\beta=0.218, \rho<0.05)$. In the third step, after entering the two components of job insecurity, the model was significant $[F(10,273)=3.139, \rho<0.01]$. R-square increased $4.8 \%$ and this change was significant $(\rho<0.01)$. The most important predictor was "importance of job security" $(\beta=0.221, \rho<0.001)$; the second important one was marital status $(\beta=0.222, \rho<0.05)$. "Worry about losing job" was not a predictor of job satisfaction. Thus, $\mathrm{H} 3 \mathrm{a}$ was rejected. Opposite to $\mathrm{H} 3 \mathrm{~b}$, the finding showed that the perceived severity of job loss (indicated by the "importance of job security") was 
positively linked to job satisfaction, thus $\mathrm{H} 3 \mathrm{~b}$ was also rejected. The findings also showed that marriage increased job satisfaction.

$<$ Table IV. Hierarchical regression analysis of job insecurity about

here $>>$

\section{Discussion and contributions}

The exploratory research contributes to our understanding of job insecurity in the Chinese institutional context and, by extension, may have implications for the studies elsewhere.

First, from the equality perspective of social safety net, the research extends our understanding of the relationship between job insecurity and the safety net from crosscountry to intra-country level.

In the West, the cross-country findings by Borg and Elizur (1992), König et al. (2011), and Debus et al. (2012) attributed higher job insecurity to the weaker social safety net of that country. On the intra-country level, only focusing on temporary employment in the Chinese SOEs, Shi (2015) tested and confirmed this negative relationship. This research, covering both permeant and temporary employees, found that the rural registered employees provided with less support from the social safety net had higher job insecurity. This is in line with the previous findings. In China, resting on 
the household registration system, the social safety net impacts rural registered employees mainly through two unequal configurations: one is limiting their access to SOE permanent employment; the other is providing them with weaker social welfare. In the former situation, rural registered employees are most likely being temporary employees who are at the higher risk of redundancy, they would perceive their likelihood of job loss is high. In the latter situation, with weaker support from social welfare and benefits, rural registered employees have less ability to cope with their possible job loss, they would perceive the loss is severe. As a result, rural registered employees suffer higher job insecurity than the urban registered ones.

Second, the research contributes to the study into the relationship between job insecurity and employment contract. There are two major categories of literature in this area. Klein Hesselink and Van Vuuren, (1999) and Parker et al. (2002) found that temporary employment leads to higher job insecurity because of the higher likelihood of redundancy. On the contrary, Klandermans et al. (1991, 2010) and Jacobson (1991) argued that, for temporary employees, the perceived possibility of job loss is high, while the perceived severity of the loss is low because they are expecting their contract will be terminated and are used to this kind of working and living style. Thus, they argued temporary employees' overall job insecurity is no higher than permanent employees'. At the beginning, the analysis of this research found that employment contract is not a 
predictor of job insecurity, which seems to be in line with the latter authors. However, the analysis of employees' self-evaluation found their concern on employment contract significantly impact their job insecurity. Considering the unequal configurations of the Chinese social safety net, this research has different explanations to the seemingly contradictory findings from any of the two categories of literature.

The research firstly suggests two levels of influential factors upon job insecurity: the macro level factors including the institutional configurations of social safety net, and the micro level factors including employment contract, and working and living style. The research secondly considers that the influence from the macro level factors is fundamental while the influence from the micro level is comparatively apparent. Thirdly, when the macro level factors equally cover all the employees, the micro level factors may manifest significant influence on employees' job insecurity.

In the first category of the literature, the findings by Klein Hesselink and Van Vuuren (1999) and Parker et al. (2002) were respectively based on the Netherlands and the United Kingdom. Compared to China, at the macro level, these two countries' institutional configurations of social safety net do not cause much inequality between temporary and permanent employees. On that equal basis, employment contract at the micro level may manifest a significant impact on job insecurity. That might be why they found temporary employees had higher job insecurity. However, at the macro level in 
China, the institutional configurations of household registration in relation to social safety net cause remarkable inequality between the employees; hence, the impact from the macro level is dominant. This might be why the rural registered employees were found to have higher job insecurity. Under this situation, employment contract, as a micro level factor, its influence on job insecurity does not show up. This might be why the regression analysis at the beginning of the analysis could not find significant influence from employment contract. Although no significant influence was found, the connection between employment contract and job insecurity still existed. That might be why in employees' self-evaluation the analysis found employees' concern on employment contract significantly impacting their worry about losing job. That might be also why the descriptive analysis found employment contract, rather than household registration, was ranked in the top three reasons for job insecurity by both rural and temporary employee groups. It may indicate that, compared to macro level factors such as household registration, micro level factors such like employment contrat are more apparent.

Regarding the second category of the literature, Klandermans, et al. (1991, 2010) and Jacobson (1991) considered employee's working and living style might cause temporary and permanent employees have the similar level of job insecurity. If taking employee's working and living style as one of the micro level factors, it will be in 
consistent with the findings of this research. Working and living style, similar to employment contract, is one of the micro level factors, might influence job insecurity significantly. However, as this research suggested, if the macro level institutional inequality exists, the macro level factors will dominant the impact, therefore, the micro level factors may not show significant influence. This could explain why household registration showed its impact in the research while working and living style showed its influence in the findings by Klandermans, et al. and Jacobson. Certainly, at the micro level, there is a range of factors such as employment contract, working and living style, gender, and marital status. Further studies are required about how, and in what situation, these factors significantly influence job insecurity. Hence, from the perspectives of macro and micro levels, this research deepens the understanding of the influence from institutional configurations and employment contract upon job insecurity.

As far as the relationship between job insecurity and satisfaction is concerned, the uniqueness of this research is that it separates the two components of job insecurity and then respectively studies their links to job satisfaction. Of the two components of job insecurity, the perceived severity of job loss (indicated by the importance of job security) was found to be positively linked to job satisfaction: the higher the consideration of the perceived severity, the higher the satisfaction. This is opposite to the findings by Ashford et al. (1989) and Reisel et al. (2010). 
The research firstly argues that the influences from the macro level factors such as social safety net and labour market must be considered. Secondly, under the macro level influences, the outcomes of job such as financial income and professional development should be considered. China has been experiencing great economic changes and its labour market becomes very competitive. In addition, China's social safety net is weak. In this macro environment, a job in relation to its financial outcome would be important to the employee, and the perceived loss of the job would be severe. Hence the employee might appreciate the present job and keep a high level of satisfaction-it explains the finding. From this perspective, it could also explain the finding that married (including partnership) employees had higher job satisfaction than their counterparts: to maintain their families, for the same reason, they might highly appreciate their jobs and get higher satisfaction. Thus, the research contributes to the understanding of the relationship between job insecurity and satisfaction under the macro level situations.

\section{Conclusion, implication, limitation and future study}

In conclusion, the exploratory research suggests that there are two levels of factors influencing job insecurity: at the macro level, the factors include the institutional configurations of social safety net; at the micro level, the factors include employment contract, and working and living style. The macro level factors have fundamental 
influence on job insecurity, which is shown in the relationship between the household registration and job insecurity in the Chinese SOEs. The micro level factors are more apparent than the macro level factors. When the macro level factors equally cover all employees, the micro level factors such as employment contract and working and living style may decide the levels of job insecurity.

Of the two components of job insecurity, the perceived severity of job loss is found to be positively linked to job satisfaction. The research argues that, under a weak social safety net in a competitive labour market, the perceived severity may cause the employees to appreciate their present jobs and then to maintain a high level of satisfaction.

The findings of the research provide a meaning to a country's effort to eliminate its social inequality: improving the equality of social safety net may also improve the job security of vulnerable employees. The world economy is in a period of volatility. Increasing redundancy and temporary employment make job insecurity a concern. To minimize the negative influence of job insecurity, improving the equal coverage and good quality of the social safety net may be a solution. As far as China's reform is concerned, household registration is a basis to access social safety net. This unequal institutional configuration should be taken into account to improve employees' job security. 
One limitation of the research is the measurement of job insecurity due to the exploratory nature of the study. This research uses single indicator respectively measuring two facets of job insecurity. Though researchers accept using single indicator, some argue that multi-indicator measurement typically has the better internal consistency (Sverke et al., 2002). Thus, extensive research using mature multi-indicator to measure multi-facet of job insecurity is required. Another limitation is in relation to the size and coverage of sampling. As China is such a big country, there are considerable differences between its regions. Nevertheless, the limited samples were only collected in the east and northeast of China. Hence they might not fully represent the overall Chinese SOEs. The research did not find any job insecurity difference between the five selected industries. It might be because the data were collected during a period of fast economic growth, in which employment situation was similar and good in all these industries. A longitude research in the future may overcome the limitation.

In the last decade, China has been modifying its social safety net, improving equality between different social and working groups. Thus, longitude comparison for future research is recommended. It would be interesting to see if the insecurity difference between rural and urban registered employees is decreasing and if it is increasing between temporary and permanent employees. It would also be interesting to study the subject in non-state owned organizations. The research suggests that 
employment contract and working and living style are micro level influential factors; at this level, how the two factors intermediate and influence job insecurity would be a subject for future study. The research finds a positive influence from one of the two components of job insecurity upon job satisfaction in a specific macro level situation. The future research could study how this influence varies under different macro level situations.

\section{Acknowledgement:}

I want to thank Professor [name will be given as soon as the paper is accepted] for his guidance on this research, especially in the early stages, and for his help with academic writing.

\section{References:}

Ashford, S.J., Lee, C. and Bobko, P. (1989), “Content, Causes, and Consequences of Job Insecurity: A Theory-based Measure and Substantive Test", Academy of Management Journal, Vol. 32 No. 4, pp. 803-829.

Bian, Y. (2002), “Chinese Social Stratification and Social Mobility”, Annual Review of Sociology, pp. 26-91.

Blank, R. M. (1994), Social Protection Versus Economic Flexibility: Is There a Tradeoff? Chicago: University of Chicago Press.

Borg, I. and Elizur, D. (1992), “Job Insecurity: Correlates, Moderators and Measurement”, International Journal of Manpower, Vol. 13 No.2, pp. 13-26. 
Brislin, R. (1980), “Translation and Content Analysis of Oral and Written Material," in: Triandis, H. C. and Berry, J. W. (eds.), Handbook of Cross-Cultural Psychology, Vol. 2, pp. 389-444. Boston: Allyn and Bacon.

Chan, A.; Madsen, R. and Unger, J. (1992), Chen Village under Mao and Deng, Berkeley: University of California Press.

Cheng, G. and Chan, D. (2008), "Who Suffers More from Job Insecurity? A Metaanalytic Review", Applied Psychology: An International Review. Vol. 57, No. 2, pp. $272-303$.

Coyle-Shapiro, J. A.-M., \& Kessler, I. (2000), “Consequences of the Psychological Contract for the Employment Relationship: A Large Scale Survey”, Journal of Management Studies, Vol. 37, pp. 903-930.

Cully, M. and Woodland, S. (1999), Britain at Work: as Depicted by 1998 Workplace Employee Relations Survey. London: Routlege.

Debus, M.E., Probst, T.M., König, C.J. and Kleinmann, M. (2012), “Catch Me If I Fall! Enacted Uncertainty Avoidance and the Social Safety Net as Country-Level Moderators in the Job Insecurity-Job Attitudes Link", Journal of Applied Psychology, Vol. 97, No. 3, pp. 690-698.

De Cuyper, N. and De Witte, H. (2007), “Job Insecurity in Temporary versus Permanent Workers: Associations with Attitudes, Well-being, and Behaviour", Work and Stress, Vol. 21 No. 1, pp. 65-84

De Witte, H., De Cuyper, N., Handaja, Y., Sverke, M., Näswall, K. and Hellgren, J. (2010), “Associations between Quantitative and Qualitative Job Insecurity and Well-being: A Test in Belgian Banks”, International Studies of Management and Organization, Vol. 40 No. 1, pp. 40-56. 
Frenkel, S. J. (2001), “Globalization, Athletic Footwear Commodity Chains and Employment Relations in China”, Organization Studies, Vol. 22 No. 4, pp. 531562.

Greenhalgh, L. and Rosenblatt, Z. (1984), “Job Insecurity: Toward Conceptual Clarity”, Academy of Management Review, Vol. 3, pp. 438-448.

Greenhalgh, L., \& Rosenblatt, Z. (2010), "Evolution of Research on Job Insecurity”, International Studies of Management and Organization, Vol. 40 No. 1, pp. 619.

Jacobson, D. (1991), “The Conceptual Approach to Job Insecurity”, in: Hartley, J., Jacobson, D., Klandermans, B., and Van Vuuren, T. (eds) Job Insecurity: Coping with Jobs at Risk. London: Sage, pp. 23-39.

Klandermans, B., Van Vuuren, T., and Jacobson, D. (1991), “Employees and Job Insecurity”, in: Hartley, J., Jacobson, D., Klandermans, B., and Van Vuuren, T. (eds) Job Insecurity: Coping with Jobs at Risk. London: Sage, pp. 40-64.

Klandermans, B., Hessellnk, J.K. and Van Vuuren, T. (2010), "Employment Status and Job Insecurity: On the Subjective Appraisal of an Objective Status”, Economic and Industrial Democracy, Vol. 31 No. 4, pp. 557-577.

Klein Hesselink, D.J. and Van Vuuren, T. (1999), “Job Flexibility and Job Insecurity: The Dutch Case”, European Journal of Work and Organizational Psychology, Vol. 8 No. 2, pp. 273-294.

König, C. J., Probst, T. M., Staffen, S., and Graso, M. (2011), “A Swiss-U.S. Comparison of the Correlates of Job Insecurity”, Applied Psychology, Vol. 60, pp. $141-159$.

Lazarus, R. S. and Folkman, S. (1984), Stress, Appraisal, and Coping. New York, NY: Springer. 
Lee, C., Bobko, P., Ashford, S., Chen, Z.X. and Ren, X. (2008), “Cross - cultural development of an abridged job insecurity measure", Journal of Organizational Behavior, Vol. 29, No. 3, pp.373-390.

Li, Q. (2001), “Market Transition and the Intergenerational Transformation of Middle Classes," in: Bian, Y., Tu, E. and So, A. (eds.), Survey Research in Chinese Societies, pp. 141-164. Hong Kong: Oxford University Press.

Liu, Z. (2005), "Institution and Inequality: the Hukou System in China", Journal of Comparative Economics, Vol. 33, pp. 133-157.

Parker, S.K., Griffin, M.A., Sprigg, C.A. and Wall, T.A. (2002), "Effect of Temporary Contracts on Perceived Work Characteristics and Job Strain: A Longitudinal Study", Personnel Psychology, Vol. 55 No. 3, pp. 689-717.

Probst, T.M. (2003), "Development and Validation of the Job Security Index and the Job Security Satisfaction Scale: A Classical Test Theory and IRT Approach”, Journal of Occupational and Organizational Psychology, Vol. 76, pp. 451-467.

Shi, Bing (2015), "Insecure, but Satisfied and Committed: the Influence of Household Registration upon Temporary Employees in Chinese State-owned Enterprises”, The International Journal of Management and Business, Vol.6 No.1, pp. 84100.

Solinger, D. J. (1999), “Demolishing Partitions: Back to Beginnings in the Cities?" China Quarterly, Vol. 159, pp. 629-639.

Solinger, D. J. (2006), “The Creation of a New Underclass in China and its Implications", Environment and Urbanization, Vol. 18 No. 1, pp. 177-193.

Sverke, M., Hellgren, J., \& Na“swall, K. (2002), "No Security: A Meta-analysis and Review of Job Insecurity and Its Consequences”, Journal of Occupational Health Psychology, Vol. 7, pp. 242-264. 
Walder, A. G. (1995), “Career Mobility and the Communist Political Order”, American Sociology Review, Vol. 60, pp. 309-328.

Wang Fei-Ling (2004), “Hukou Systems and Migration Control”, in: Chen, A., Liu, G. G. and Zhung, K. H. (eds.), Urban Transformation in China. Surrey: Ashgate Publishing Limited.

Whyte, M. K. (2010), “The Paradoxes of Rural-Urban Inequality in Contemporary China", in: Whyte, M. K. (ed.), One Country, Two Societies: Rural-Urban Inequality in Contemporary China (Harvard Contemporary China Series 16. Cambridge: Harvard University Press.

Wong, Y.T., Wong, C.S., Ngo, H.Y. and Lui, H.K. (2005), "Different responses to job insecurity of Chinese workers in joint ventures and state-owned enterprises", Human Relations, Vol. 58, No.11, pp.1391-1418.

Zheng, B. and Sun, S. (2008), “30 Years Institutional Reform of China”s Social Security", in: Zou, D. and Ouyang, R. (eds.) China: 30 Years of Reform and Opening-up (1978-2008). Beijing: Social Sciences Academic Press. 
Table I. Pearson correlations between selected factors in relation to job insecurity and satisfaction

\begin{tabular}{|c|c|c|c|c|c|c|c|c|c|c|c|c|c|c|}
\hline & $\mathbf{M}$ & SD & $\mathbf{N}$ & 1 & 2 & 3 & 4 & 5 & 6 & 7 & 8 & 9 & 10 & 11 \\
\hline $\begin{array}{l}\text { 1. Worry about } \\
\text { losing job }\end{array}$ & .06 & 1.020 & 309 & 1 & $.239 * *$ & -0.37 & $-.288 * *$ & -.010 & $-.141^{*}$ & $.188^{* *}$ & $.237^{* *}$ & .077 & $.189 * *$ & .097 \\
\hline $\begin{array}{l}\text { 2. Importance of } \\
\text { job security }\end{array}$ & 1.17 & .770 & 308 & & 1 & $.198^{* *}$ & $-.127^{*}$ & .038 & -.032 & .103 & $.187^{* *}$ & .074 & $.148^{* *}$ & .085 \\
\hline 3. Job satisfaction & .102 & .703 & 308 & & & 1 & -.082 & $.115^{*}$ & .005 & $.129^{*}$ & $.155^{* *}$ & $.209^{* *}$ & $.160^{* *}$ & $.127^{*}$ \\
\hline 4. Household registration & .87 & .336 & 309 & & & & 1 & $.239^{* *}$ & -.085 & $.265^{* *}$ & -.025 & .082 & .023 & $.134^{*}$ \\
\hline 5. Employment contract & .69 & .465 & 305 & & & & & 1 & -.012 & $.160^{* *}$ & $.433^{* *}$ & $.381^{* *}$ & $.416^{* *}$ & $.432^{* *}$ \\
\hline 6. Gender & .47 & .500 & 294 & & & & & & 1 & -.026 & .017 & $-.120^{*}$ & -.017 & .087 \\
\hline 7. Age & 2.28 & .919 & 309 & & & & & & & 1 & $.826^{* *}$ & $.575^{* *}$ & $.685^{* *}$ & $.399 * *$ \\
\hline 8. Working years & 2.45 & 1.129 & 309 & & & & & & & & 1 & $.623^{* *}$ & $.751^{* *}$ & $.468^{* *}$ \\
\hline 9. Marital status & .72 & .449 & 308 & & & & & & & & & 1 & $.727 * *$ & $.415^{* *}$ \\
\hline 10. Parental status & .60 & .490 & 306 & & & & & & & & & & 1 & $.499^{* *}$ \\
\hline 11. Trade union member & .52 & .500 & 303 & & & & & & & & & & & 1 \\
\hline \multicolumn{15}{|c|}{ Notes: household registration: $0=$ rural registration, 1=urban registration; employment contract: $0=$ temporary contract, $1=$ permanent contract; gender: } \\
\hline $\begin{array}{l}0=\text { female, } 1=\text { male; age: } 1=25 \text { a } \\
\text { years, } 4=21-30 \text { years, } 5=31-40 \\
0=\text { no, } 1=y e s ; \text { trade union mem }\end{array}$ & $\begin{array}{l}\text { nd belo } \\
\text { years, } 6 \\
\text { ber: } 0=\end{array}$ & $\begin{array}{l}2=26-3 \\
11 \text { years } \\
1=\text { yes }\end{array}$ & $\begin{array}{l}5,3=3 \\
\text { and a }\end{array}$ & & $\begin{array}{l}-55,5=5 \\
\text { cance: }{ }^{*} p\end{array}$ & $\begin{array}{l}-65,6=66 \\
0=\text { single } \\
<.05 ; * *\end{array}$ & $\begin{array}{l}\text { and abov } \\
\text { /separate, } \\
0<.01\end{array}$ & $\begin{array}{l}\text {; workin } \\
\text { Nidower }\end{array}$ & $\begin{array}{l}\text { years: } 1 \\
\text { divorced }\end{array}$ & 5 years a & $\begin{array}{l}\text { nd below, } \\
\text { d / in part }\end{array}$ & $\begin{array}{l}2=6-10 y \\
\text { nership; }\end{array}$ & $\begin{array}{l}\text { ears, } 3=11 \\
\text { parental st }\end{array}$ & $\begin{array}{l}-20 \\
\text { atus: }\end{array}$ \\
\hline
\end{tabular}


Table II. Hierarchical regression analysis of job insecurity, household registration, and employment contract

\begin{tabular}{|c|c|c|c|c|c|c|}
\hline \multirow[b]{2}{*}{ Independent variables } & \multicolumn{3}{|c|}{ Worry about losing job } & \multicolumn{3}{|c|}{ Importance of job security } \\
\hline & $\beta$ & $R^{2}$ & $\Delta R^{2}$ & $\beta$ & $R^{2}$ & $\Delta R^{2}$ \\
\hline Step 1 & & .092 & $.092^{\star \star *}$ & & .043 & .043 \\
\hline Gender & $-.162^{\star \star}$ & & & -.047 & & \\
\hline Age & -.042 & & & -.132 & & \\
\hline Working Year & $.267^{*}$ & & & .231 & & \\
\hline Marital status & $-.204^{*}$ & & & -.111 & & \\
\hline Parental status & .160 & & & .139 & & \\
\hline Trade union membership & .005 & & & .023 & & \\
\hline Step 2 & & .194 & $.102^{* * *}$ & & .056 & $.013^{*}$ \\
\hline Gender & $-.194^{\star *}$ & & & -.059 & & \\
\hline Age & .025 & & & -.108 & & \\
\hline Working Year & .179 & & & .199 & & \\
\hline Marital status & $-.173^{*}$ & & & -.100 & & \\
\hline Parental status & .128 & & & .127 & & \\
\hline Trade union membership & .064 & & & .045 & & \\
\hline Household registration & $-.328^{\star * *}$ & & & $-.119^{*}$ & & \\
\hline Step 3 & & .201 & .007 & & .056 & .000 \\
\hline Gender & $-.195^{\star \star *}$ & & & -.059 & & \\
\hline Age & .040 & & & -.106 & & \\
\hline Working Year & .190 & & & .200 & & \\
\hline Marital status & $-.167^{*}$ & & & -.100 & & \\
\hline Parental status & .135 & & & .128 & & \\
\hline Trade union membership & .084 & & & .047 & & \\
\hline Household registration & $-.309^{\star * *}$ & & & -.117 & & \\
\hline Employment contract & -.097 & & & -.010 & & \\
\hline
\end{tabular}

Notes: unstandardized betas at the final step are reported; $N=283$; statistical significance: ${ }^{*} \mathrm{p}$ $<.05 ;{ }^{* *} p<.01 ;{ }^{* * *} p<.001$. 
Table III. Self-evaluation of the top three reasons for job insecurity

\begin{tabular}{lclc}
\hline \multicolumn{2}{c}{ Rural registered employees } & \multicolumn{2}{c}{ Urban registered employees } \\
1. Education & 52.5 & 1. Industrial situation & 52.6 \\
2. Industrial situation & 45.0 & 2. Education & 40.9 \\
3. Employment contract & 42.5 & 3. Economy & 35.4 \\
\hline \multicolumn{1}{c}{ Temporary employees } & \multicolumn{1}{c}{ Permanent employees } \\
1. Employment contract & 61.5 & 1. Industrial situation & 62.5 \\
2. Education & 45.8 & 2. Education & 41.8 \\
3. Practical skill & 37.6 & 3. Economy & 41.8 \\
\hline Notes: the number beside each factor is the total percentage of rank 1, 2 and \\
3 from that group.
\end{tabular}


Table IV. Hierarchical regression analysis of job satisfaction

\begin{tabular}{|c|c|c|c|c|c|c|c|c|c|}
\hline \multirow[b]{2}{*}{ Independent variables } & \multicolumn{3}{|c|}{ Step 1} & \multicolumn{3}{|c|}{ Step 2} & \multicolumn{3}{|c|}{ Step 3} \\
\hline & $\beta$ & $R^{2}$ & $\Delta R^{2}$ & $\beta$ & $R^{2}$ & $\Delta R^{2}$ & $\beta$ & $R^{2}$ & $\Delta R^{2}$ \\
\hline & & .042 & .042 & & .055 & .013 & & .103 & $.048 * *$ \\
\hline Gender & .007 & & & -.002 & & & -.009 & & \\
\hline Age & .007 & & & .019 & & & .046 & & \\
\hline Working Year & .064 & & & .029 & & & .005 & & \\
\hline Marital status & $.212^{\star}$ & & & $.218^{*}$ & & & $.222 \star$ & & \\
\hline Parental status & -.089 & & & -.103 & & & -.118 & & \\
\hline Trade union membership & .014 & & & .020 & & & .019 & & \\
\hline Household registration & & & & -.117 & & & -.124 & & \\
\hline Employment contract & & & & .063 & & & .055 & & \\
\hline Worry about losing job & & & & & & & -.103 & & \\
\hline Importance of job security & & & & & & & $.221 * \star *$ & & \\
\hline
\end{tabular}

Notes: unstandardized betas at the final step are reported; $N=284$; statistical significance: ${ }^{*} \mathrm{p}$ $<.05 ;{ }^{* *} p<.01 ;{ }^{* *} p<.001$. 